\title{
Quantum Mechanics Calculations: Asymmetric Phosphines for Methanol Carbonylation (Part I)
}

\section{Hirihattaya Phetmung}

Inorganic and Materials Chemistry Research Unit, Department of Chemistry, Thaksin University, Ampher Muang, Songkhla, Thailand

* tayaphetmung@yahoo.com (corresponding author)

Received in revised form $20^{\text {th }}$ August 2008, accepted $3^{\text {rd }}$ October 2008.

\begin{abstract}
This work presents quantum mechanics calculations based on density functional theory (DFT) for the newly designed asymmetric diphosphine ligand $\mathbf{1 . 1}$ that can be a promoter for methanol carbonylation. Because of its chiral centers with electron withdrawing and electron donating groups, this is the reason why the different trans-influence and trans effect of complex type " $\mathrm{Rh}(\mathrm{L}) \mathrm{L}^{\prime}(\mathbf{1 . 1})$ " would favor the formation of different isomers. Rhodium complexes 1.3, 1.4, 1.5 and 1.6 can be expected to combine high catalytic activity with thermal stability under the mild conditions of the methanol carbonylation process. The difference in energy $(\Delta \mathrm{E})$ values and the calculated equilibrium constant clearly indicate that the most stable isomer $\mathbf{1 . 5}$ is the initial catalytically active species and should be possible to prepare.
\end{abstract}

(Asymmetric phosphine, methanol carbonylation, quantum mechanics, density functional theory, catalyst)

\section{INTRODUCTION}

The carbonylation of methanol to acetic acid is one of the most important and successful industrial applications of homogeneous transition metal catalysis [1, 2]. Since its original development by Monsato about fourty years ago, a rhodium/iodide catalyzed process, so-called the Monsanto catalyst $\left[\mathrm{RhI}_{2}(\mathrm{CO})_{2}\right]^{-}, \quad$ has predominated $[3,4,5]$.

Attempts to modify this catalyst and increase its activity by introducing electron-donating ligands have been hampered by the instability of many complexes of such ligands under the harsh reaction conditions required for carbonylation. Recent reports have identified a number of mixed-donor ligands, which promote carbonylation under very mild conditions (typically $<130{ }^{\circ} \mathrm{C}$ and $<20$ bar) [6]. However, these mild conditions are not well suited to commercial operation where high absolute reaction rates are required and engineering constraints favor high temperatures and therefore higher pressures. One report has stated that the use of the diphosphinesulfide $\mathrm{Ph}_{2} \mathrm{PCH}_{2} \mathrm{P}(\mathrm{S}) \mathrm{Ph}_{2}$ (dppms) as a promoter for rhodium catalyzed methanol carbonylation allows a surprisingly substantial rate increase under industrially feasible conditions $[10,11,12]$. At $185{ }^{\circ} \mathrm{C}, 30$ atm, the rate increased eight times higher than $\left[\mathrm{RhI}_{2}(\mathrm{CO})_{2}\right]^{-}$(for commercial viability, the conditions under which the catalyst operates are crucial). Rhodium(I) carbonyl complexes containing phosphino-thiolate and -thioether ligands are almost four times as active in catalyzing the carbonylation of methanol, and the crystal structure of one procatalyst, $\left[\mathrm{Rh}\left(\mathrm{SC}_{6} \mathrm{H}_{4} \mathrm{PPh}_{2}\right)(\mathrm{CO})\right]_{2}$, has been reported $[7,8]$. The dppms ligand gives the expected fast oxidation and it also promotes the subsequent $\mathrm{CO}$ insertion step \{by a factor of $c a .3000$ compared with $\mathrm{Ph}_{2} \mathrm{PCH}_{2} \mathrm{CH}_{2} \mathrm{PPh}_{2}$ (dppe)\} [9]. Strong donor ligands, particularly phosphines, are known to accelerate the rate determining oxidative addition of methyl iodide to Rh (I) and hence promote catalysis. Rhodium complexes of unsymmetrical diphosphines of the type $\mathrm{Ph}_{2} \mathrm{PCH}_{2} \mathrm{CH}_{2} \mathrm{PAr}_{2}$ are catalysts for the carbonylation of methanol. The diphosphines, some of which are known, [10, 11, $12,13,14,15]$ were made and fully characterized (see Figure 1.). 


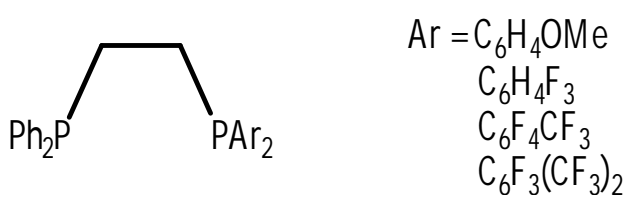

Figure 1. Some diphosphines ligands used as promoters in methanol carbonylation.

Several important homogeneous catalysts now utilize bidentate ligands for which the stereoproperties are less well understood [16]. Although the bidentate ligand "bite angle" has been shown to be important, the understanding of the observed behavior at the molecular level is incomplete and the quantification of ligand effects on individual steps from catalytic quite rare $[16,17,18]$.

In addition to the high electron density at rhodium [19], ligand steric and electronic effects play a key role in determining organometallic reactivity trends and catalytic behavior [20]. Recently, the observation of $\left[\mathrm{Rh}\left(\mathrm{Cp}^{\prime}\right.\right.$ $\left.\left(\mathrm{CH}_{2}\right)_{2} \mathrm{PEt}_{2}\right)(\mathrm{C}(\mathrm{O}) \mathrm{Me}) \mathrm{I}$ under methanol carbonylation conditions suggests that the rhodium centre has become so electron rich that the reductive elimination process has become rate determining for methanol carbonylation.

Methanol carbonylation has been studied in detail not only experimentally but also from a theoretical point of view. Computational chemistry especially quantum mechanics calculations is used as a tool to understand the mechanism and reaction [21, 22, 23]. A theoretical study of steric and electronic effects in the rhodium-catalyzed carbonylation reaction using DFT have been carried out on the catalytic cycle and found that the migratory insertion process presents an important step in methanol carbonylation [24].

The basic idea behind this work is that ligands which increase the electron density at the metal should promote an oxidative addition process. To this purpose, a ligand $\mathbf{1 . 1}$ was designed as a promoter for catalysis of a methanol carbonylation. Such a ligand can have its electronic properties tuned by a varying the constituents on one phosphorus i.e. make a 'strong-weak' ligand with one strong $\sigma$-donor (and poor $\pi$-acceptor) and one weaker $\sigma$-donor (and stronger $\pi$-acceptor). Theoretical methods are employed and investigated.

\section{EXPERIMENTAL SECTION}

The designed structures under this study are a ligand $\mathrm{PF}_{2} \mathrm{PCH}_{2} \mathrm{CH}_{2} \mathrm{PMe}_{2}$ 1.1, a cation 1.2 and complexes 1.3, 1.4, 1.5 and 1.6 as shown in Figure 2.

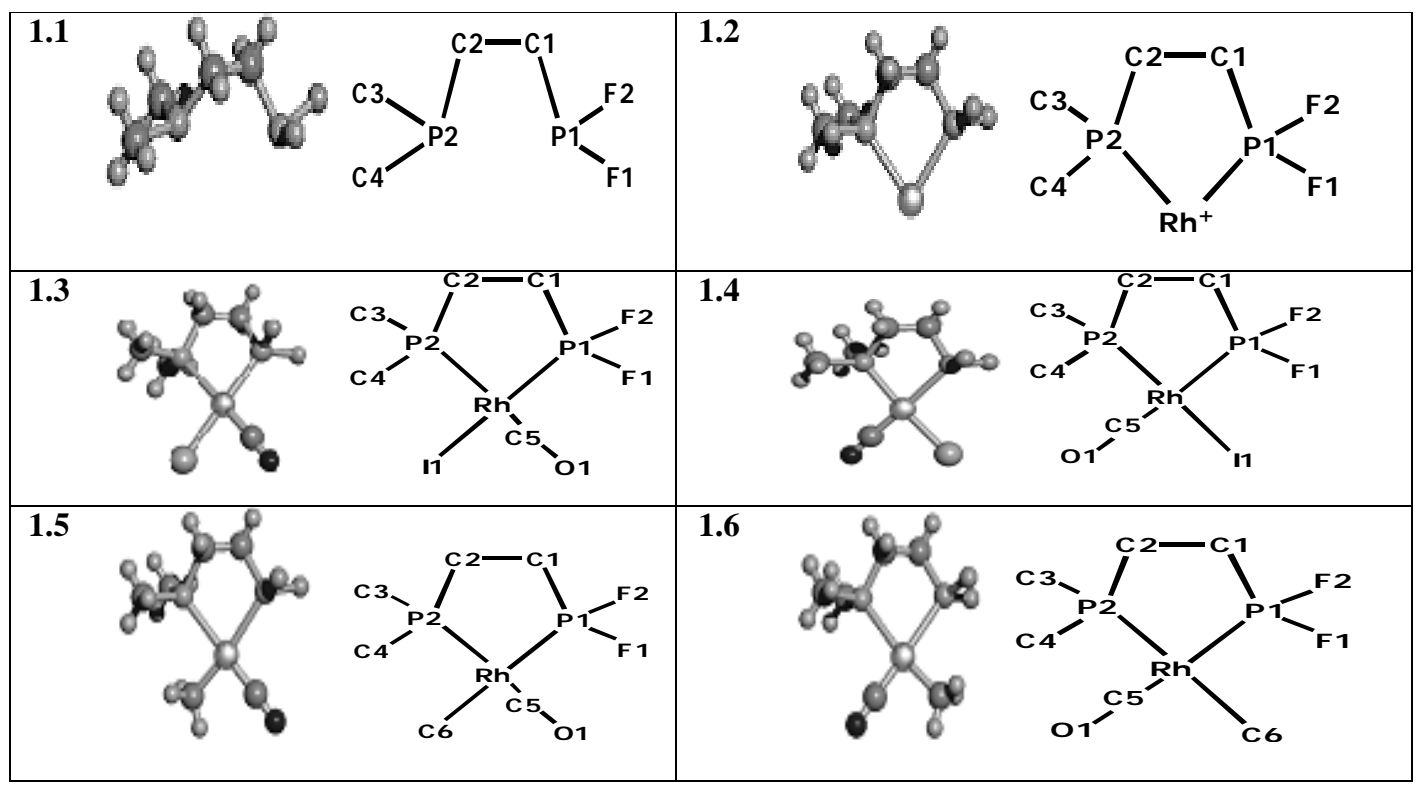

Figure 2. Designed ligand 1.1, cation 1.2, and complexes 1.3, 1.4, 1.5 and 1.6. Hydrogen atoms in Chemdraw model are omitted for clarity. 
The complexes have square planar geometry at rhodium. Isomeric complexes $\mathbf{1 . 3}$ and $\mathbf{1 . 4}$ contain $\mathrm{CO}$ and $\mathrm{I}$. The isomer $\mathbf{1 . 3}$ has CO trans to the $\mathrm{PMe}_{2}$ moiety of the ligand; this arrangement is reversed in 1.4. Complexes $\mathbf{1 . 5}$ and $\mathbf{1 . 6}$ differ from complexes $\mathbf{1 . 3}$ and $\mathbf{1 . 4}$ only in that the $\mathrm{Me}^{-}$ group replaces the $\mathrm{I}^{-}$ligand of $\mathbf{1 . 3}$ and $\mathbf{1 . 4}$. For computational methodology, initial structure geometries were constructed at the UFF level using the Cerius ${ }^{2}$ program [25]. The geometry optimizations were started from an idealized symmetric geometry with chemically equivalent bonds and angles assigned to the corresponding values from International Tables for Crystallography (ITC) [26]. All quantum mechanics calculations were performed using the Gaussian 98 program [27]. All geometries were first performed using a single point energy calculation at HF/3-21G level, as a consistency check on the molecular geometry to be used as the starting point for all subsequent calculations. Then, in order to determine suitable structure, full optimization at density functional theory (DFT) level B3LYP/LANL2DZ was performed. These optimized geometries were compared to those similar structures. The molecular orbitals yielded from these quantum mechanics calculation were generated using the GaussView program [28, 29].

\section{RESULTS AND DISCUSSION}

The Optimization of Ligand 1.1 and Cation 1.2 Based on the DFT calculation, the average P-F bond length of the asymmetric phosphine ligand 1.1 is about $0.149 \AA$ shorter than the average PMe bond length, indicative of the strong electron withdrawing effect of the $\mathrm{F}$ atoms (Table 1). F atoms are highly electronegative (ca. $-0.4735 \mathrm{au})$ and wish to obtain additional electron density. As electron-withdrawing (electronegative) groups are placed on the phosphorous atoms, the $\sigma$ donating capacity of the phosphine ligand tends to decrease. At the same time, the energy of the $\pi$-acceptor $\left(\sigma^{*}\right)$ on phosphorous is lowered in energy, providing an increase in backbonding ability [24]. The highest occupied molecular orbital (HOMO) has stronger lone pairs on $\mathrm{PMe}_{2}$ than that on $\mathrm{PF}_{2}$. The stronger electronic property on $\mathrm{PF}_{2}$ is favored for a lowest unoccupied molecular orbital (LUMO) as shown in Figure 3. Thus one can conclude that $\mathrm{PF}_{2}$ is poorer $\sigma$ donor, but a better $\pi$-acceptor. The HOMOLUMO gap energy is large $(+0.2153$ au $)$ confirming that the ligand is not planar $[30,31]$.

Table 1. : The optimized parameters of $\mathbf{1 . 1}$ and $\mathbf{1 . 2}$

\begin{tabular}{lcccccc}
\hline PARAMETER $^{\mathbf{a}}$ & $\mathbf{1 . 1}$ & $\mathbf{1 . 2}$ & $\mathbf{1 . 3}$ & $\mathbf{1 . 4}$ & $\mathbf{1 . 5}$ & $\mathbf{1 . 6}$ \\
\hline P1-C1 & 1.894 & 1.874 & - & - & - & - \\
P1-F1 & 1.745 & 1.724 & - & - & - & - \\
P2-C2 & 1.923 & - & - & - & - & - \\
Rh-P1 & - & 2.232 & 2.286 & 2.380 & 2.357 & 2.507 \\
Rh-P2 & - & 2.237 & 2.442 & 2.405 & 2.456 & 2.348 \\
P2-Rh-P1 & - & 106.10 & 83.42 & 82.76 & 86.20 & 86.20 \\
C2-C1-P1 & 112.60 & - & - & - & - & - \\
C1-C2-P1 & 113.27 & - & - & - & - & - \\
Energy (au) & -371.1502 & -480.5835 & -605.4811 & -605.4695 & -633.9392 & -633.9336 \\
\hline
\end{tabular}

a bond distances are in $\AA$ and bond angles are in ${ }^{\circ}$ 


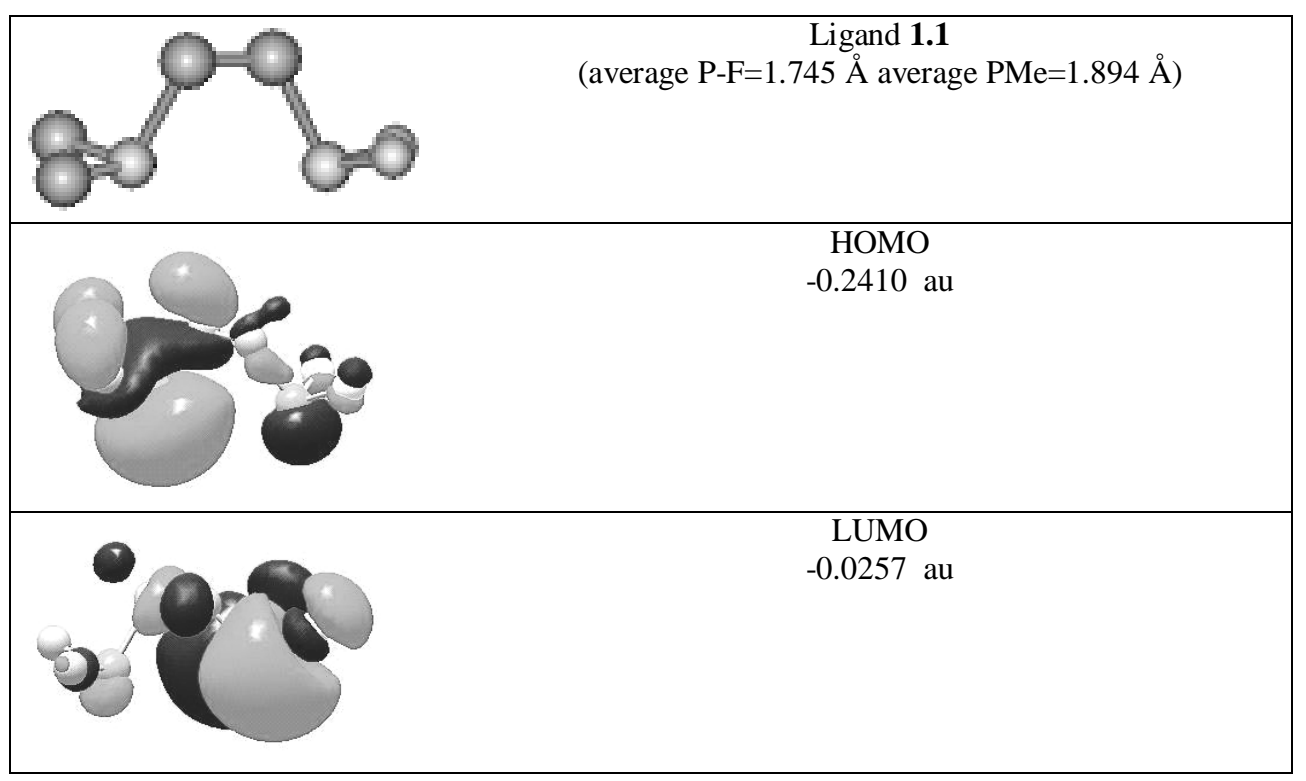

Figure 3. The asymmetric ligand $\mathbf{1 . 1}$ and its two molecular orbitals. Hydrogen atoms are omitted for clarity.

The calculated number of IR and Raman bands show the stretching frequency of the $\mathrm{PMe}_{2}$ moiety is higher than that of $\mathrm{PF}_{2}$ moiety. As already known, the higher the frequency is the greater the $\sigma$-donation [31].

Selected molecular orbitals and molecular orbital energies for the cation $\mathbf{1 . 2}$ are shown in Figure 4. The HOMO- 1 shows the $d_{x z}$ orbital and has no contribution from the asymmetric ligand 1.1. Whereas the HOMO shows the $\mathrm{d}_{\mathrm{xy}}$ orbital. It also has a contribution from the $\mathrm{PF}_{2}$ moiety of the ligand 1.1. In other words, the $\pi$ - orbital from the LUMO of ligand 1.1 contributes to the HOMO of the cation 1.2. The LUMO illustrates $\mathrm{a} \mathrm{d}_{\mathrm{x}-\mathrm{y}}^{2}$ orbital and clearly shows the relation between metal and asymmetric ligand 1.1. The other two LUMOs illustrate lone pair electrons and the $\pi$ electron of metal center. This confirms that there is less electron density on the metal center with a greater $\pi$-acidity on $\mathrm{PF}_{2}$ and a greater $\sigma$-donation on $\mathrm{PMe}_{2}$. 

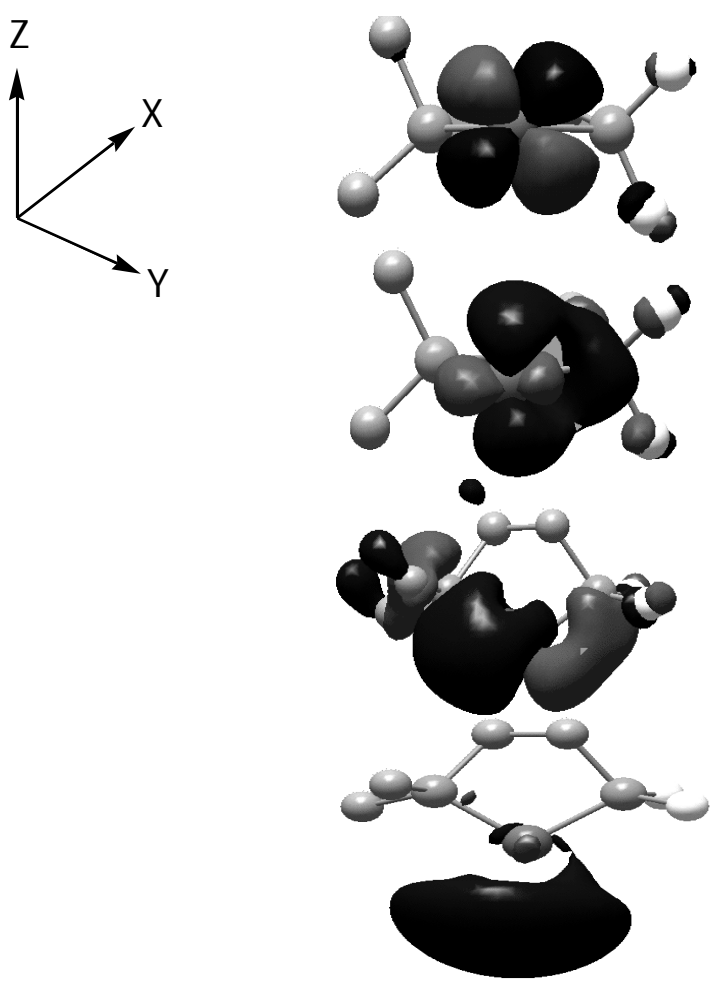

HOMO-1

$0.1863 \mathrm{au}$

HOMO

$-0.1580 \mathrm{au}$

LUMO

$-0.0451 \mathrm{au}$

LUMO+1

$-0.0213 \mathrm{au}$

Figure 4: A rhodium cation 1.2 shows the molecular orbitals. Hydrogen atoms are omitted for clarity.

The molecular orbitals of cation $\mathbf{1 . 2}$ illustrate clearly how this ligand is bonded to the metal center. It may be expected that ligand $\mathbf{1 . 1}$ can generate more than one isomer, reasoning from the different groups $\left(\mathrm{PMe}_{2}\right.$ and $\left.\mathrm{PF}_{2}\right)$. This would favor the formation of different isomers when it promotes the organometallic catalyst complex, namely complexes 1.3, 1.4, 1.5 and 1.6.

\section{The Optimization of Isomers 1.3 and 1.4}

As regards optimized structures $\mathbf{1 . 3}$ and 1.4, the Rh- $\mathrm{PMe}_{2}$ bond length in $\mathbf{1 . 3}$ is $0.037 \AA$. longer than that in 1.4, indicating the stronger transeffect of CO over I. The Rh-PF bond length is $0.094 \AA$ shorter than that in 1.4. The Rh-I bond lengths in both structures are not significantly different and are in a good agreement with typical $\mathrm{Rh}-\mathrm{I}$ distances [31]. As one can see, in $\mathbf{1 . 3}$ the $\mathrm{CO}$ ligand weakens the bond in the trans position more than $\mathrm{I}^{-}$. This is not different to the $\mathrm{Rh}-\mathrm{CO}$ distance of $\left[\mathrm{Rh}(\mathrm{CO}) \mathrm{IPh}_{2} \mathrm{P}\left(\mathrm{CH}_{2} \mathrm{CH}_{2}\right) \mathrm{PPh}_{2}\right] .{ }^{15}$ The Rh-I distance of $\mathbf{1 . 4}$ is slightly shorter than that in 1.4 but significantly longer than those in similar structures $\left[\mathrm{Rh}(\mathrm{CO}) \mathrm{IPh}_{2} \mathrm{PCH}_{2} \mathrm{PPh}_{2} \mathrm{~S}\right]$, and its isomer $\left[\mathrm{RhI}(\mathrm{CO}) \mathrm{Ph}_{2} \mathrm{PCH}_{2} \mathrm{PPh}_{2} \mathrm{~S}\right]$ [24]. This is a consequence of the poorer $\pi$-donating ability of
$\mathrm{PF}_{2}$. The bite angle of $\mathbf{1 . 3}$ is $0.64^{\circ}$ smaller than that in $\mathbf{1 . 4}$ and is about $2.27^{\circ}$ smaller than those in ref. 22 indicating less steric effects and lower energy.

The optimized free CO frequency is $2313 \mathrm{~cm}^{-1}$ with $1.143 \AA$ of bond distance (see Table 2). This number is higher than the experimental value which a free $\mathrm{CO}$ is $2143 \mathrm{~cm}^{-1}$ with a bond distance of $1.128 \AA$ from IR spectroscopy [32]. Because of the nature of the computation involved, frequencies are valid only stationary points on the PES. Raw frequency values computed at the DFT level contain systematic errors due to the neglect of electron correlation, resulting in overestimates of about $0-10 \%$. Therefore, it is usual to scale frequencies predicted at DFT level by an empirical factor of 0.9623 . Use of this factor has been demonstrated to produce very good agreement with experiment. For this calculation, it is about $200 \mathrm{~cm}^{-1}$ higher which is the typical from such a calculation [28, 29]. 
Table 2: $\quad$ Number of IR and Raman CO stretching frequencies of series 1

\begin{tabular}{lccccc}
\hline \multicolumn{1}{c}{ CO } & $\boldsymbol{v C O}$ & $\mathbf{d}(\AA)$ & STRUCTURES & vCO & d $(\mathbf{A})$ \\
\hline Free CO & 2143 & 1.128 & $\mathbf{1 . 3}$ & 2000.4 & 1.173 \\
Terminal CO & $1850-2120$ & $1.12-1.18$ & $\mathbf{1 . 4}$ & 1973.4 & 1.177 \\
Doubly bridging CO & $1700-1860$ & - & $\mathbf{1 . 5}$ & 1965.1 & 1.179 \\
This work & 2313.0 & 1.143 & $\mathbf{1 . 6}$ & 1934.8 & 1.174 \\
\hline
\end{tabular}

The IR and Raman CO stretching frequencies of isomers 1.3 at $2000.4 \mathrm{~cm}^{-1}$ can be observed. This number is higher than that of $\mathbf{1 . 4}$ at $1973.4 \mathrm{~cm}^{-1}$. It is a typical number for a terminal $\mathrm{CO}$ group $[28,29]$. The calculated free $\mathrm{CO}$ distance is about $1.143 \AA$ while those of structures $\mathbf{1 . 3}$ and $\mathbf{1 . 4}$ are $1.173 \AA$ and $1.177 \AA$ respectively. The lower $1.143 \AA$ distance is due to back donation. This occupation of the $\pi^{*}$ on CO does lead to a decreased bond order in the carbon monoxide molecule itself. As we might expect, as the $\pi$ backdonation becomes stronger, the $\mathrm{CO}$ bond order should decrease from that of the free ligand. Two consequences that might be expected if the $\mathrm{CO}$ bond order was reduced would be a lengthening of the $\mathrm{C}-\mathrm{O}$ bond and a decrease in the carbonyl stretching frequency in the IR. Again, the higher the $\mathrm{vCO}$ stretching frequency the weaker the $\sigma$-donation.

The DFT/LANL2DZ calculated energies of complex $\mathbf{1 . 3}$ are lower than that in complex 1.4, indicating the more stable complex $\mathbf{1 . 3}$ than complex 1.4 (see Table 1). The different energy $(\Delta \mathrm{E})$ values were used to calculate the equilibrium constant. By using the equation of $\Delta \mathrm{G}=-\mathrm{RT} \operatorname{lnK}$, where $\Delta \mathrm{G}$ is free energy change $(\mathrm{kcal} / \mathrm{mol}), \quad \mathrm{R}$ is the gas constant $(1.987$ $\mathrm{cal} / \mathrm{mol} / \mathrm{K}), \mathrm{T}$ is room temperature $(298 \mathrm{~K})$ and $\mathrm{K}$ is equilibrium constant. Assuming that $\Delta \mathrm{G} \sim \Delta \mathrm{H}=$ $\sim 7.28 \mathrm{kcal} / \mathrm{mol}$ the ratio of $\mathbf{1 . 3 : 1 . 4}$ is $c a$. 218530:1.

\section{The Optimization of Isomers 1.5 and 1.6}

As regards optimized structures $\mathbf{1 . 5}$ and 1.6, the Rh-PMe and the Rh-PF bond length in $\mathbf{1 . 5}$ are $0.01 \AA$ longer than that in 1.6. The Rh-CO distances in both structures are essentially the same. This is a consequence of poorer $\pi$-donating property of $\mathrm{PF}_{2}$. Surprisingly, the bite angle of $\mathbf{1 . 5}$ is $1.07^{\circ}$ bigger than that in $\mathbf{1 . 5}$ and is in a good agreement with work done by Casey et al. [10].

However isomer $\mathbf{1 . 5}$ with methyl group trans to a good electron withdrawing group is preferred. Isomer 1.5 is about $29 \mathrm{kcal} / \mathrm{mol}$ lower in energy than isomer 1.3. This confirms that the presence of strongly electronegative fluorine atoms in $\mathrm{PF}_{2}$ makes them weak $\sigma$-donors but much stronger $\pi$ acceptors and the presence of methyl groups in $\mathrm{PMe}_{2}$ make them stronger $\sigma$-donors but much weaker $\pi$ - acceptors. This is also indicated by the IR and Raman CO frequencies which are in the range of the terminal carbonyl group. However, the stretching frequency of $\mathbf{1 . 5}$ is at $1965.1 \mathrm{~cm}^{-1}$ and is higher than that of $\mathbf{1 . 6}$ at $1934.8 \mathrm{~cm}^{-1}$. It corresponds with a slightly longer $\mathrm{CO}$ bond distance. The slightly longer $\mathrm{C}-\mathrm{O}$ bond distance in $1.5(1.179 \AA)$ and the lower $\mathrm{C}$-O frequency $\left(1916.1 \mathrm{~cm}^{-1}\right)$ indicate more $\mathrm{Rh}=\mathrm{C}=\mathrm{O}$ character [12].

The energy value of complex $\mathbf{1 . 5}$ is lower than 1.6 by $\sim 3.51 \mathrm{kcal} / \mathrm{mol}$, implying $\Delta \mathrm{G} \sim \Delta \mathrm{H}=-3.51$ $\mathrm{kcal} / \mathrm{mol}$ and therefore a ratio of 1.5:1.6 is ca. 380:1. This is to confirm that complex $\mathbf{1 . 5}$ is slightly more stable than complex 1.6.

\section{The Comparison Energies of Isomers 1.3 and 1.5}

The P-Me $\mathrm{Me}_{2}$ bond distances of the two isomers $\mathbf{1 . 3}$ and $\mathbf{1 . 5}$ are about the same. That is because they are trans to the strong electron withdrawing $\mathrm{CO}$ group. The difference is in the $\mathrm{Rh}-\mathrm{PF}_{2}$ bond distances. The $\mathrm{Rh}-\mathrm{PF}_{2}$ bond lengths in $\mathbf{1 . 5}$ are about $0.07 \AA$ higher than that in $\mathbf{1 . 3}$, indicating the stronger trans-effect of the $\mathrm{CH}_{3}{ }^{-}$group over I.

The IR and Raman CO stretching frequencies are in the range for a terminal carbonyl group. However, the frequency for $\mathbf{1 . 3}$ is about $88 \mathrm{~cm}^{-1}$ higher than that of 1.5. This corresponds well with the slightly shorter of $\mathrm{CO}$ bond distance, indicating more $\mathrm{Rh}=\mathrm{C}=\mathrm{O}$ character. In other words, the slightly longer $\mathrm{C}-\mathrm{O}$ bond distance in $1.5(1.179 \AA)$ is related to the lower $\mathrm{C}-\mathrm{O}$ frequency $\left(1916.1 \mathrm{~cm}^{-1}\right)$

The calculated optimization energy values of complex $\mathbf{1 . 5}$ is lower than $\mathbf{1 . 3}$ by $\sim 1785.7$ $\mathrm{kcal} / \mathrm{mol}$. This implies that $\mathbf{1 . 5}$ is more stable than 1.3. 
To confirm the electronic effects at work, analysis of the molecular orbital is needed (see Figure 5.). The HOMO-1 shows the $\mathrm{d}_{\mathrm{yz}}$-orbital with $\pi$-bond on the $\mathrm{CH}_{3}$. The HOMO is $\mathrm{a} \mathrm{d}_{\mathrm{z}}{ }^{2}$ orbital and has the contribution from the $\mathrm{CH}_{3}$ group ( $\sigma$-donation). LUMO+1 is $\mathrm{a} \mathrm{d}_{\mathrm{x}}^{2}{ }^{2}{ }^{2}$ orbital and shows not only the $\mathrm{Rh}=\mathrm{C}=\mathrm{O}$ character, confirmed by the shorter $\mathrm{Rh}-\mathrm{C}(\mathrm{O})$ bond distance. The LUMO+1 also shows a $\pi$-bond on the $\mathrm{PF}_{2}$
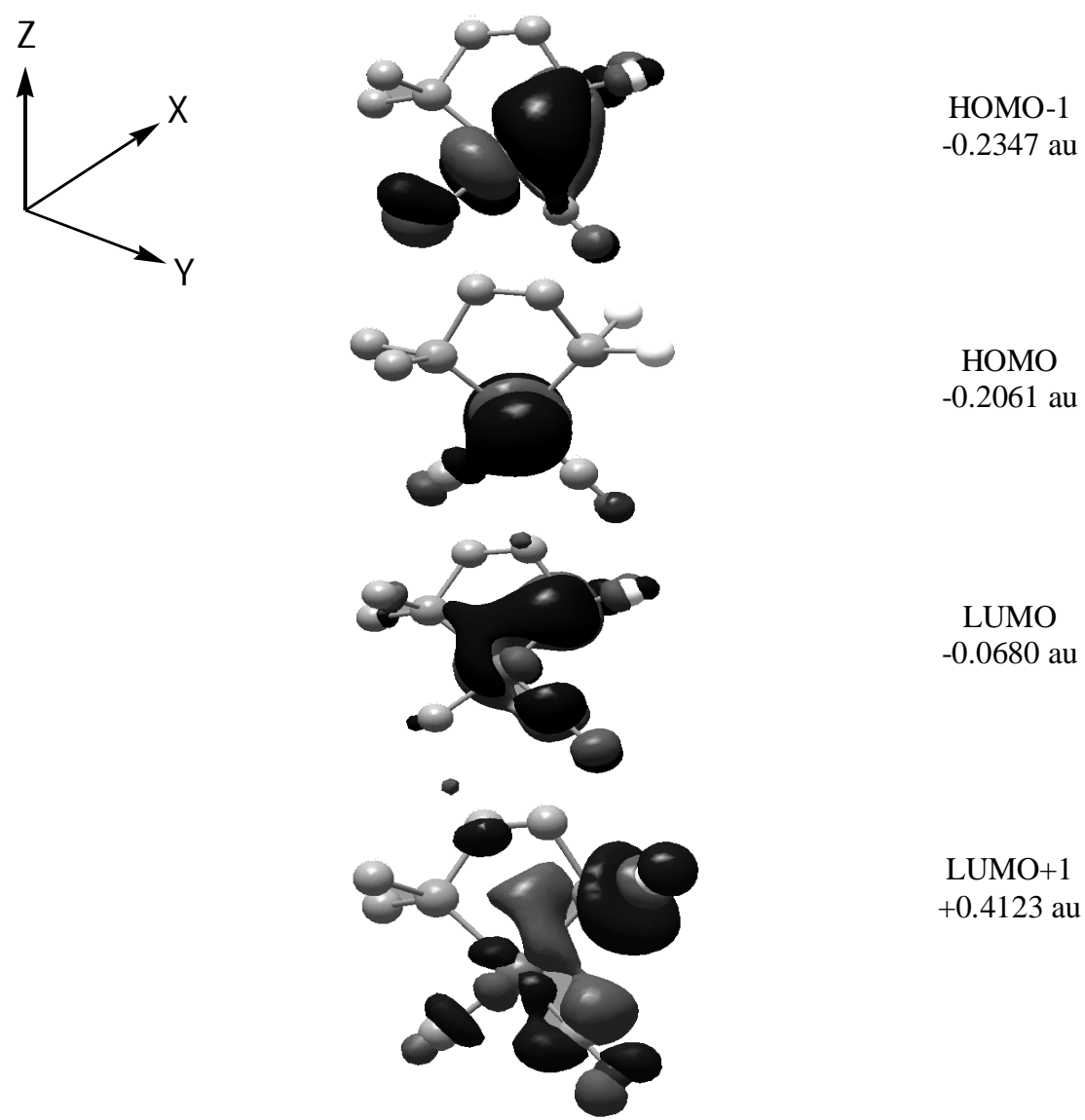

Figure 5: Some molecular orbitals of complex 1.5. Hydrogen atoms are omitted for clarity.

The rhodium complex $\mathbf{1 . 5}$ shows a cis-squareplanar geometry with a bite angle of $82.64^{\circ}$. The computed structures all confirm that the preferred stereochemistry at rhodium is that in which the $\mathrm{PMe}_{2}$ is trans to the carbonyl and the $\mathrm{PF}_{2}$ lays trans to the methyl group. The presence of the highly electronegative fluorine atoms in $\mathrm{PF}_{2}$ makes the phosphorus a weak $\sigma$-donor but a stronger $\pi$ - acceptor and the presence of methyl groups in $\mathrm{PMe}_{2}$ makes it a stronger $\sigma$-donor but a weaker $\pi$-acceptor, consistent the variation in $\mathrm{Rh}$ $\mathrm{P}$ bond lengths. This is a consequence of the moiety. The LUMO+2 shows the $\mathrm{d}_{\mathrm{xy}}$ on metal with the $\mathrm{Rh}=\mathrm{C}=\mathrm{O}$ character or $\pi$ - backbonding. The results from DFT/LANL2DZ are in a good agreement. The molecular orbital analysis confirms that an $\mathrm{d}_{\mathrm{z}}{ }^{2}$ orbital is lower in energy than the $\mathrm{d}_{\mathrm{x}-\mathrm{y}}^{2}$ orbital as expected for a low-spin $\mathrm{d}^{8}$ orbital $\mathrm{Rh}(\mathrm{I})$ configuration [10].
HOMO-1

HOMO

LUMO

$0.0680 \mathrm{au}$

LUMO+1

$0.4123 \mathrm{au}$

electron-donating properties of the $\mathrm{PMe}_{2}$ moiety, which increases the electron density at the metal center and as a consequence the $\mathrm{Rh}$ to $\mathrm{CO}$ backbonding (more $\mathrm{Rh}=\mathrm{C}=\mathrm{O}$ character), also indicated by the IR and Raman CO frequencies. It is clearly confirmed that isomer $\mathbf{1 . 5}$ is a good structure for such a series and as regards optimized energy, isomer $\mathbf{1 . 5}$ has the lowest energy from the all four rhodium complexes. 


\section{CONCLUSIONS}

Quantum mechanics calculation based on density functional theory (DFT) were carried out for an asymmetric phosphine ligand $\mathrm{PF}_{2} \mathrm{PCH}_{2} \mathrm{CH}_{2} \mathrm{PMe}_{2}$ 1.1. This ligand was employed as a promoter of the rhodium catalyzed methanol carbonylation. A rhodium cation 1.2 and complexes 1.3, 1.4, 1.5 and 1.6 were investigated in the gas phase based on electronic properties to specify the most stabilization structure.

The B3LYP/LANL2DZ calculated energy of complex 1.5 was lower than those in complexes 1.3, 1.4 and 1.6, confirming the most stable structure. The stereochemistry at rhodium in which the $\mathrm{PMe}_{2}$ trans to the $\mathrm{CO}$ and the $\mathrm{PF}_{2}$ lies trans to the Me group was preferred. The results indicated that the presence of the strong electronegative fluorine atoms in $\mathrm{PF}_{2}$ made them weak $\sigma$-donors but much stronger $\pi$ - acceptors and the presence of $\mathrm{Me}$ groups in $\mathrm{PMe}_{2}$ made them stronger $\sigma$-donors but much weaker $\pi$ acceptors, confirmed by the bond distances of 2.356 and $2.456 \AA$ for $\mathrm{Rh}-\mathrm{PF}_{2}$ and $\mathrm{Rh}-\mathrm{PMe}_{2}$ respectively in complex $\mathbf{1 . 5}$. The electronic property results from B3LYP /LANL2DZ were in a good agreement. All considered complexes adopted a square-planar geometry. The molecular orbital analysis confirmed that the $\mathrm{d}_{\mathrm{z}}{ }^{2}$ orbital was lower energy than $\mathrm{d}_{\mathrm{x}-\mathrm{y}}^{2}{ }^{2}$ orbital as expected for a low-spin $d^{8}$ orbital Rh (I) configuration.

\section{ACKNOWLEDGEMENTS}

I gratefully thank Prof. Dr. Tom Ziegler from the University of Calgary, Canada, for his helpful suggestions. This work was supported by the Thailand Research Fund (TRF).

\section{REFERENCES}

1. Gauss, M., Seidel, A., Torrence, P. and Heymans, P. (1996). In: Applied Homogeneous Catalysis with Organometallic Compounds (eds. Cornils, B. and Herrmann, W. A.). VCH, New York

2. Haynes, A., Maitlis, P. M., Morris, G. E., Sunley, G. J., Adams, H., Badger, P. W., Bowers, C. M., Cook, D. B., Elliott, P. I. P., Ghaffar, T., Green, H., Griffin, T. R., Payne, M., Pearson, J. M., Taylor, M. J., Vickers, P. W., and Wat, R. J. (2004). Promotion of iridium-catalyzed methanol carbonylation:
Mechanistic studies of the Cativa process. $J$. Am. Chem. Soc. 126 (9): 2847 - 2861.

3. Howard, M. J., Jones, M. D., Roberts, M. S. and Taylor, S. A. (1993). $C_{1}$ to acetyls: Catalysis and process. Catalysis Today 18: $325-354$.

4. Paulik, F. E., Roth, J. F. (1968). Novel catalysts for the low-pressure carbonylation of methanol to acetic acid. J. Chem. Soc. Chem. Commun. 1578.

5. Roth, J. F., Craddock, J. H., Hershman, A. and Paulik, F. E. (1971). Chem. Tech. 600

6. Wegman, R. W., Abatjoglou, A. G. and Harrison, A. M. (1987). Carbonylation of methanol at unusually low temperature and pressure with cis$\mathrm{RhCl}(\mathrm{CO})_{2} \mathrm{Ph}_{2} \mathrm{P}\left(\mathrm{CH}_{2}\right)_{2} \mathrm{P}(\mathrm{O}) \mathrm{Ph}_{2} \quad J$. Chem. Soc., Chem. Commun. 1891 - 1892.

7. Baker, M. J., Giles, M. F., Orpen, A. G., Taylor, M. J. and Watt, R. J. (1995). Cis[RhI $\left.(\mathrm{CO})\left(\mathrm{Ph}_{2} \mathrm{PCH}_{2} \mathrm{P}(\mathrm{S}) \mathrm{Ph}_{2}\right)\right]$ : A new catalyst for methanol carbonylation. J. Chem. Soc, Chem. Commun. 197 - 198.

8. Dilworth, J. R., Miller, J. R., Wheatley, N., Baker, M. J. and Sunley, G. J. (1995). Novel catalysts for the carbonylation of methanol. J. Chem. Soc. Chem. Commun. 1579 - 1581.

9. Gonsalvi, L., Adams, H., Synley, G. J., Ditzel, E. and Haynes, A. (1999). J. Am. Chem. Soc. A dramatic steric effect on the rate of migratory $\mathrm{CO}$ insertion on Rhodium. 121 (49): 11233

10. Casey, C. P., Paulsen, E. L., Beuttenmueller, B. W., Proft, B. R., Matter, B. A. and Powell, D. R. (1999). J. Am. Chem. Soc. Electronically dissymmetric DIPHOS derivatives give higher $n: i$ regioselectivity in Rhodium-catalyzed hydroformylation Than either of their symmetric counterparts. 121 (1): $63-70$ and references therein.

11. Brunner, H. and Stumpf, A. (1993). Optisch aktive Übergangsmetall-Komplexe CV. Faciale und meridionale Chromcarbonylphosphin-Komplexe. J. Organomet. Chem. 459: 139

12. Kapoor, P. N., Pathak, D. D., Gaur, G. and Kutty, M. (1984). Synthesis of three new ditertiary phosphines: 1-Diphenylphosphino2-bis( $m$-fluorophenyl)phosphinoethane, 1diphenylphosphino-2-bis $(p$ -

fluorophenyl)phosphinoethane and 1diphenylphosphino-2-m-

bis(trifluoromethyl)phenylphosphinoethane. J. Organomet. Chem. 276: 167 - 170. 
13. Pearson, J. M., Haynes, A., Morris, G. E., Sunley, G. J. and Maitlis, P. M. (1995). Dramatic acceleration of migratory insertion in $\left[\mathrm{MeIr}(\mathrm{CO})_{2} \mathrm{I}_{3}\right]^{-}$by methanol and by tin(II) iodide. J. Chem. Soc., Chem. Commun. 1045

14. Ghaffar, T., Adams, H., Maitlis, P. M., Sunley, G. J., Baker, M. J. and Haynes, A. (1998). Spectroscopic identification and reactivity of $\left[\operatorname{Ir}(\mathrm{CO})_{3} \mathrm{I}_{2} \mathrm{Me}\right]$, a key reactive intermediate in iridium catalysed methanol carbonylation. J. Chem. Soc., Chem. Commun. 1023 - 1024.

15. Howard, M. J., Synley, G. J., Boole, A. D., Watt, R. J. and Sharma, B. K. (1999) Stud. Surf. Sci. Catal. 121: 61

16. Shriver, D. F., Atkin, P. W. and Langford, C. H. (1990). Inorganic Chemistry, Oxford University Press, England.

17. Dierkes, P. and van Leeuwen, P. W. N. M. (1999). The bite angle makes the difference: a practical ligand parameter for diphosphine ligands. J. Chem. Soc., Dalton Trans. 10: $1519-1530$.

18. Casey, C. P., Paulsen, E. L., Beuttenmueller, E. W., Proft, B. R., Petrovich, L. M., Matter, B. A. and Powell, D. R. (1997). Electron withdrawing substituents on equatorial and apical phosphines have opposite effects on the regioselectivity of Rhodium catalyzed hydroformylation. J. Am. Chem. Soc. 119: 11817 - 11825 .

19. McConnell, A. C., Pogorzel, P. J., Slawin, A. M. Z., William, G. L., Elliott, P. I. P., Haynes, A., Marr, A. C. and Cole-Hamilton, D. J. (2006). The synthesis, characterisation and reactivity of 2phosphanylethylcyclopentadienyl complexes of cobalt, rhodium and iridium. Dalton Trans. $91-107$

20. Hermann, W. A., Cornils, B. (1999). The synthesis, characterisation and reactivity of 2-phosphanylethylcyclopentadienyl complexes of cobalt, rhodium and iridium Applied Homogeneous Catalysis with Organometallic Compounds, VCH Weinheim

21. Matsubara, T., Koga, N., Ding, Y., Musaev, D. G. and Morokuma, K. (1997). Ab Initio
MO Study of the Full Cycle of Olefin Hydroformylation Catalyzed by a Rhodium Complex, $\mathrm{RhH}(\mathrm{CO})_{2}\left(\mathrm{PH}_{3}\right)_{2}$. Organomettalics 16: 1065 - 1078.

22. Cheong, M., Schmid, R. and Ziegler, T. (2000). Density Functional Study of the Migratory Insertion Step in the Carbonylation of Methanol Catalyzed by $\left[\mathrm{M}(\mathrm{CO})_{2} \mathrm{I}_{2}\right]^{-}(\mathrm{M}=\mathrm{Rh}, \mathrm{Ir})$. Organometallics 19: 1973

23. Cheong, M. and Ziegler, T. (2005). Density Functional Study of the Oxidative Addition Step in the Carbonylation of Methanol Catalyzed by $\left[\mathrm{M}(\mathrm{CO})_{2} \mathrm{I}_{2}\right]^{-}(\mathrm{M}=\mathrm{Rh}$, Ir $)$. Organometallics 24: 3053 - 3058

24. Cavallo, L. and Sola, M. (2001). A theoretical study of steric and electronic effects in the Rhodium-catalyzed carbonylation reactions. J. Am. Chem. Soc. 123: 12294 - 12302.

25. Cerius ${ }^{2}$ Molecular Modelling Software. MSI/Biosym Inc., Cambridge, UK

26. Janssen, T., Janner, A., Looijenga-Vos, A. and de Wolff, P. M. (2004) International tables for crystallography, Vol. C, $3^{\text {rd }}$ ed., (ed. Prince, E.), Kluwer Academic Publishers, Dordrecht

27. Frisch, M. J., Frisch, A. E. and Foresman, J. B. (1999) Gaussain 98 User's Reference, Gaussian Inc., Pittsburgh.

28. Neilson, A. B. and Holder, A. J. (2001) GaussView: Version 2 User's Reference, Gaussian Inc. Pittsburgh.

29. Neilson, A. B. and Holder, A. J. (1998) GaussView's User Reference, Gaussian Inc. Pittsburgh

30. Gilheany, D. G. (1994). Ylides, phosphoniumNo d Orbitals but Walsh Diagrams and Maybe Banana Bonds: Chemical Bonding in Phosphines, Phosphine Oxides, and Phosphonium Ylides. Chem. Rev. 94: 1339

31. Gimarc, B. M. (1979). Molecular Structure and Bonding. Academic Press New York

32. Miessler, G. L. and Tarr, D. A. (1991) Inorganic Chemistry Prentice-Hall Inc. New Jersey. 